Chromosome 1

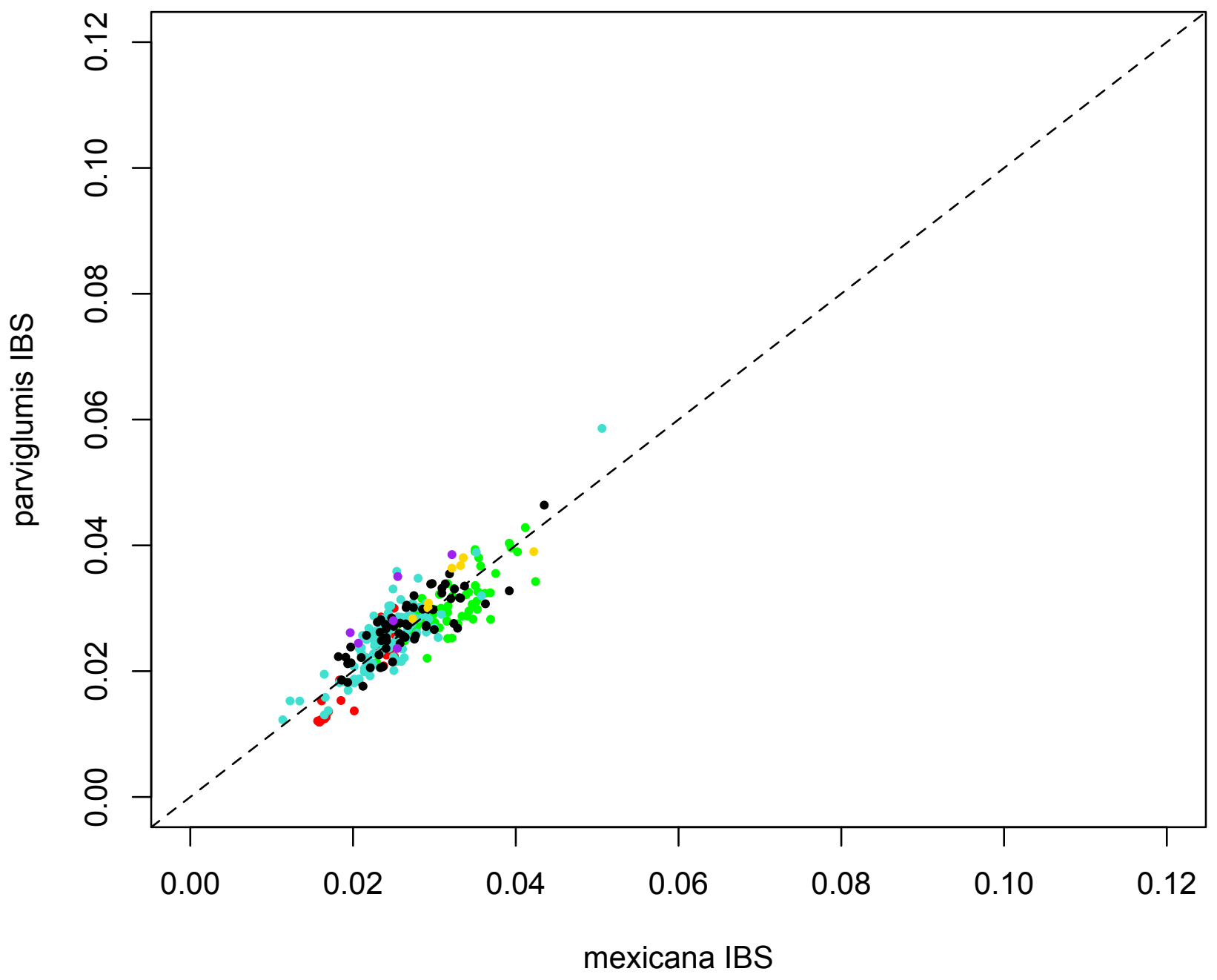


Chromosome 2

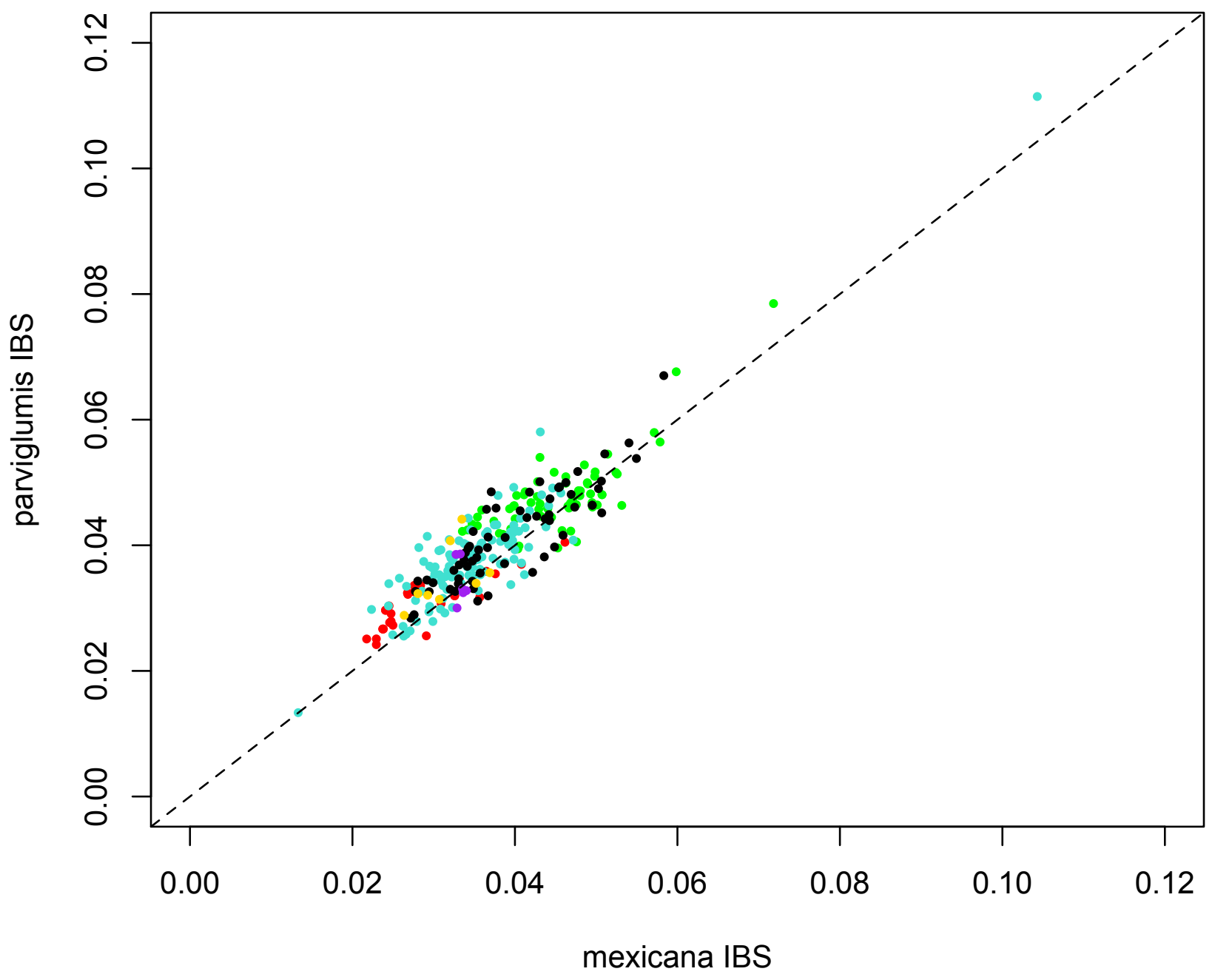


Chromosome 3

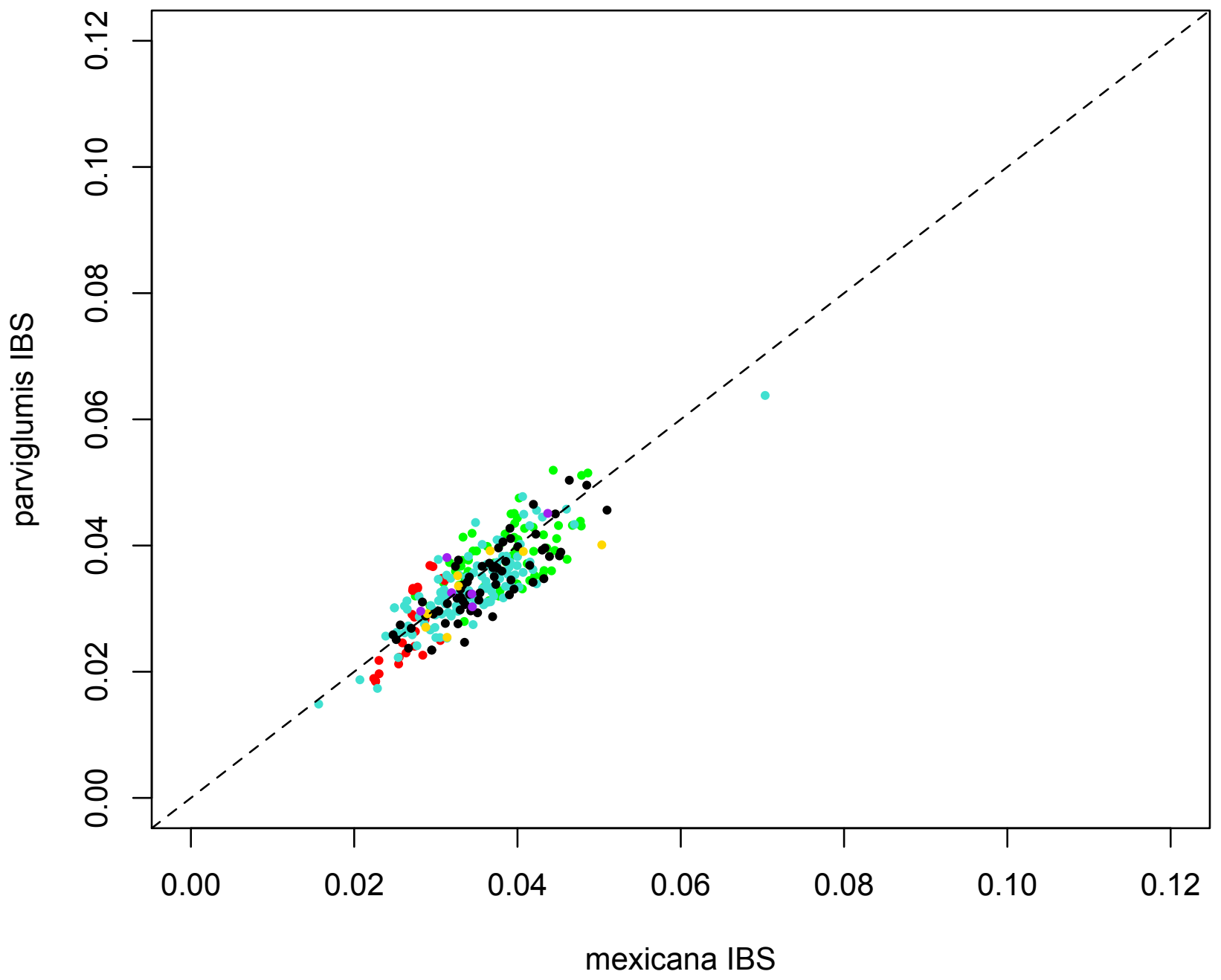


Chromosome 4

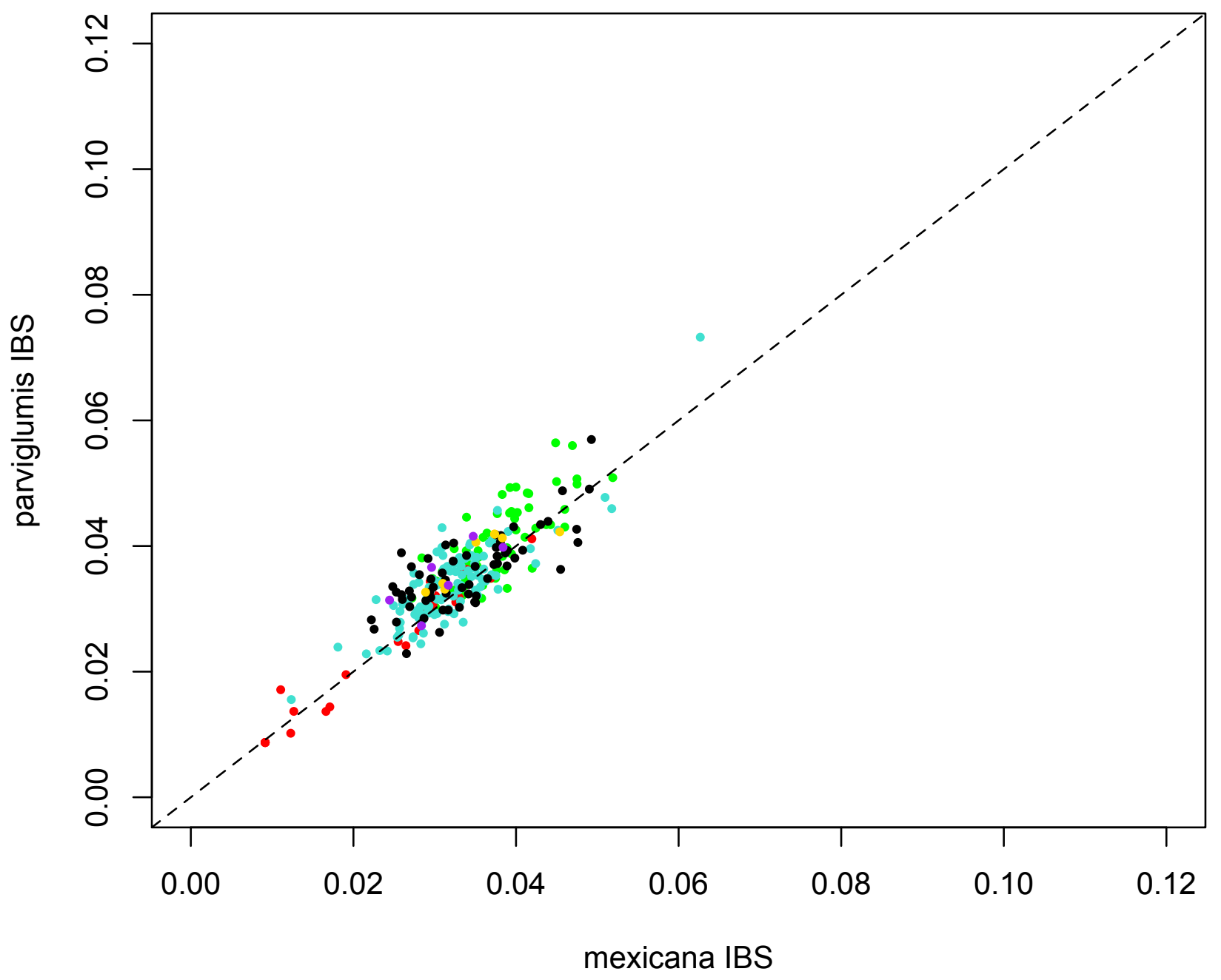


Chromosome 5

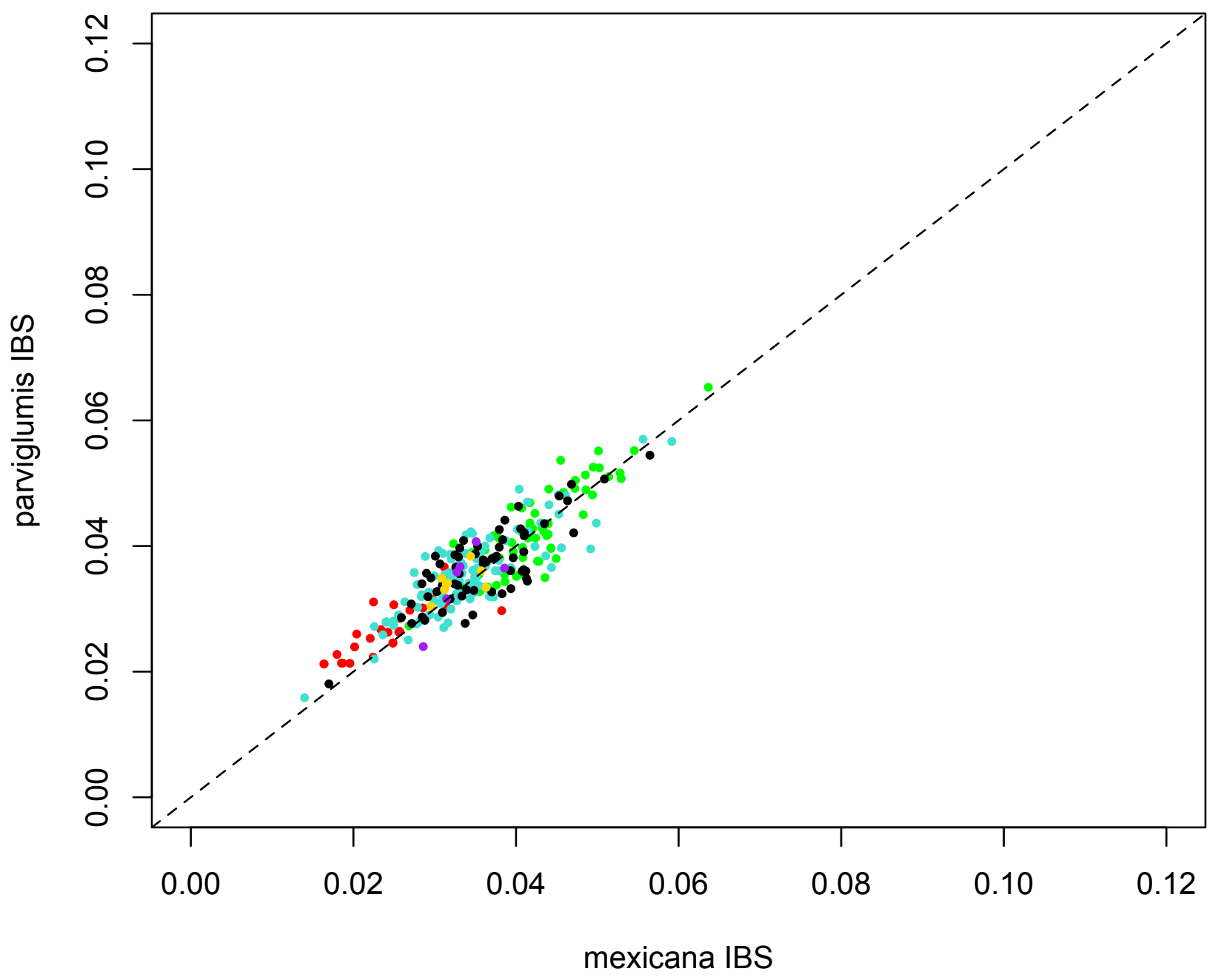


Chromosome 6

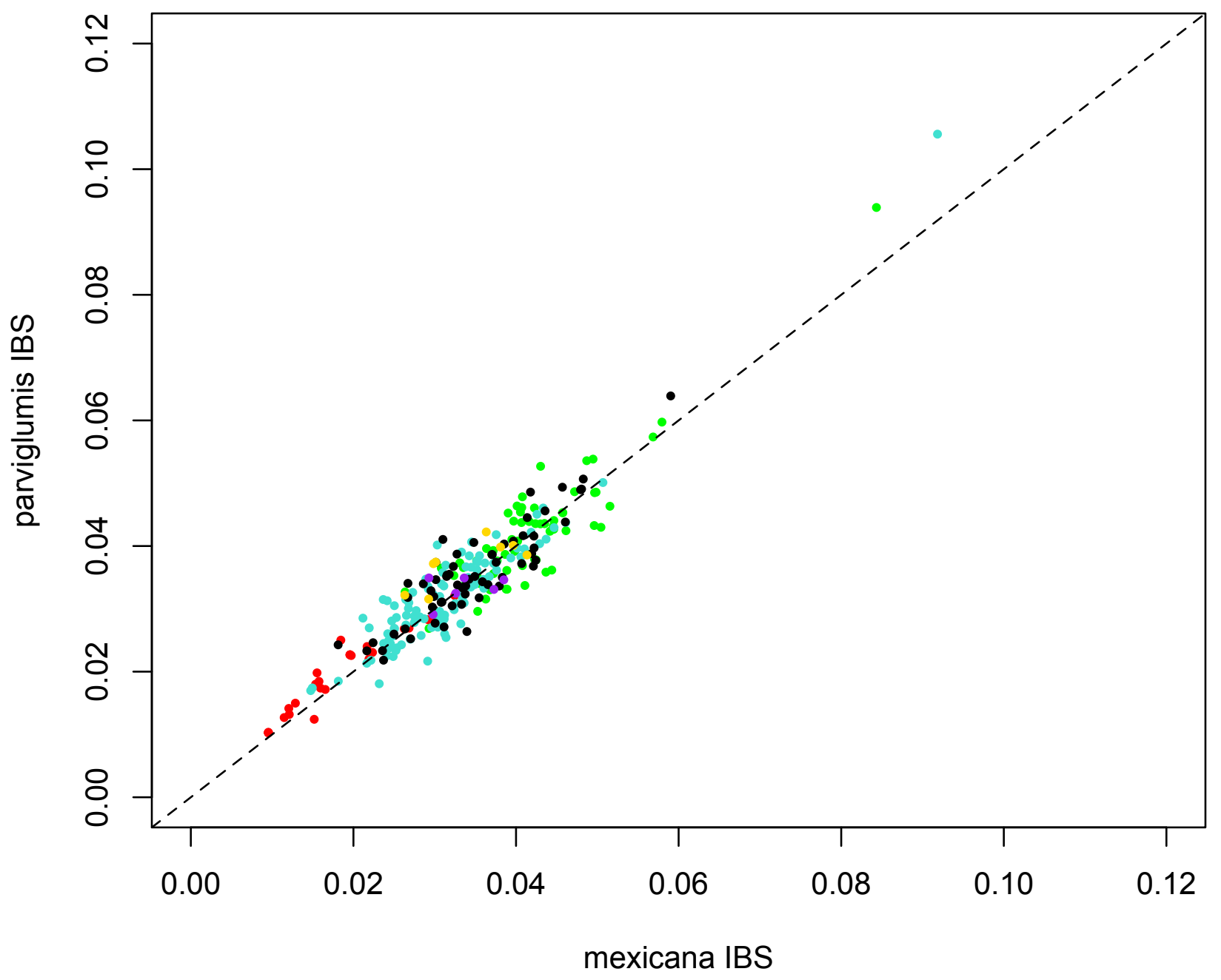




\section{Chromosome 7}

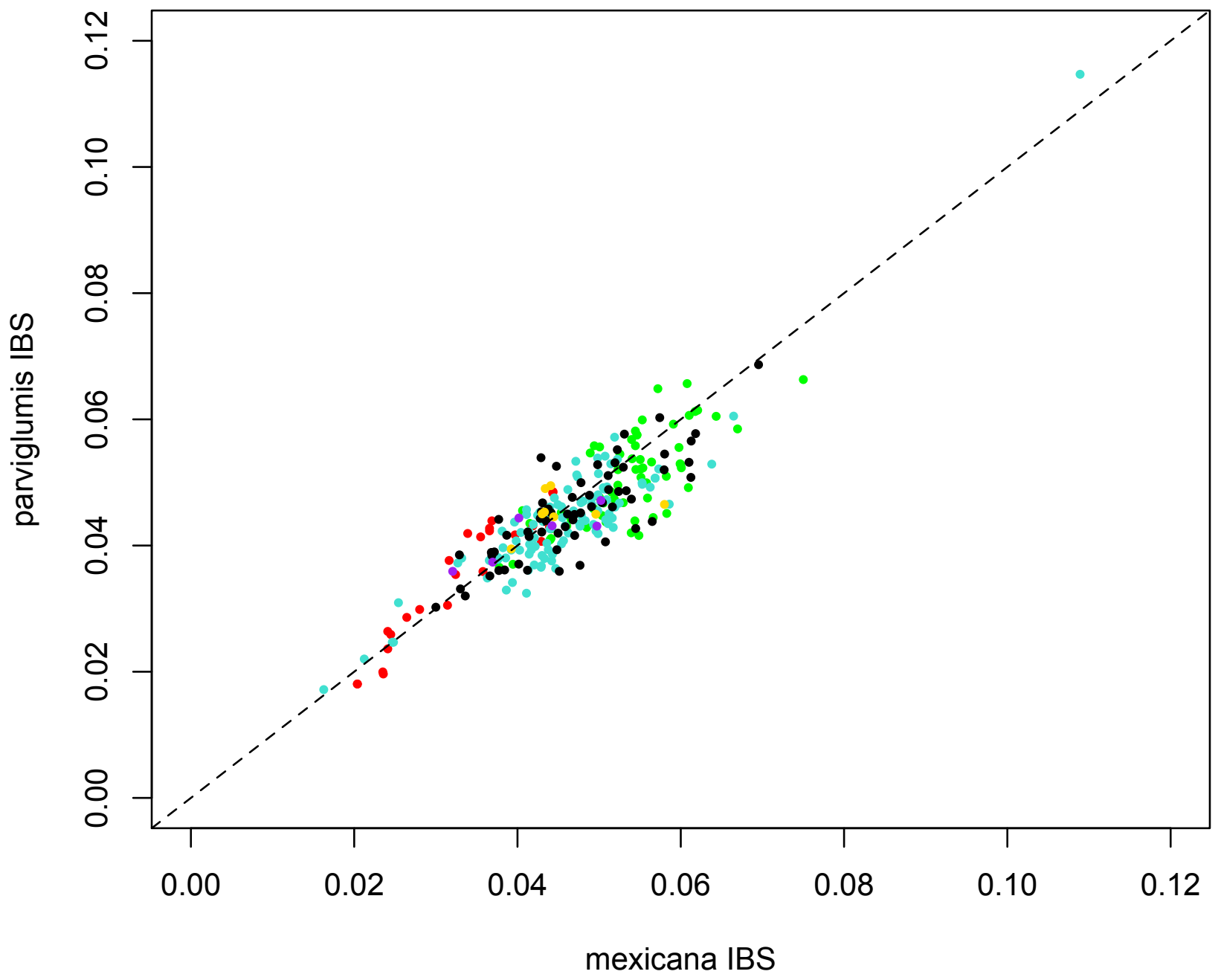


Chromosome 8

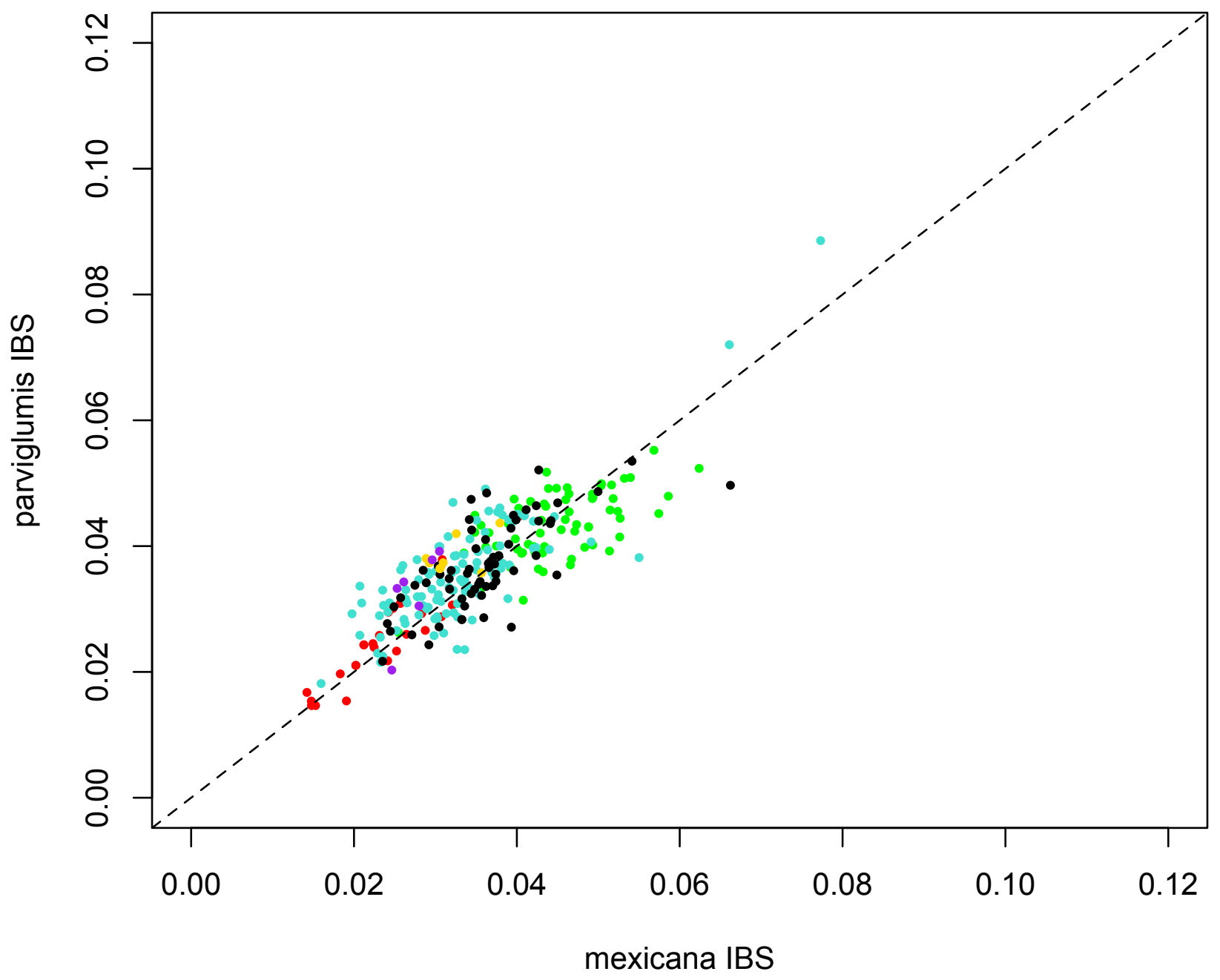




\section{Chromosome 10}

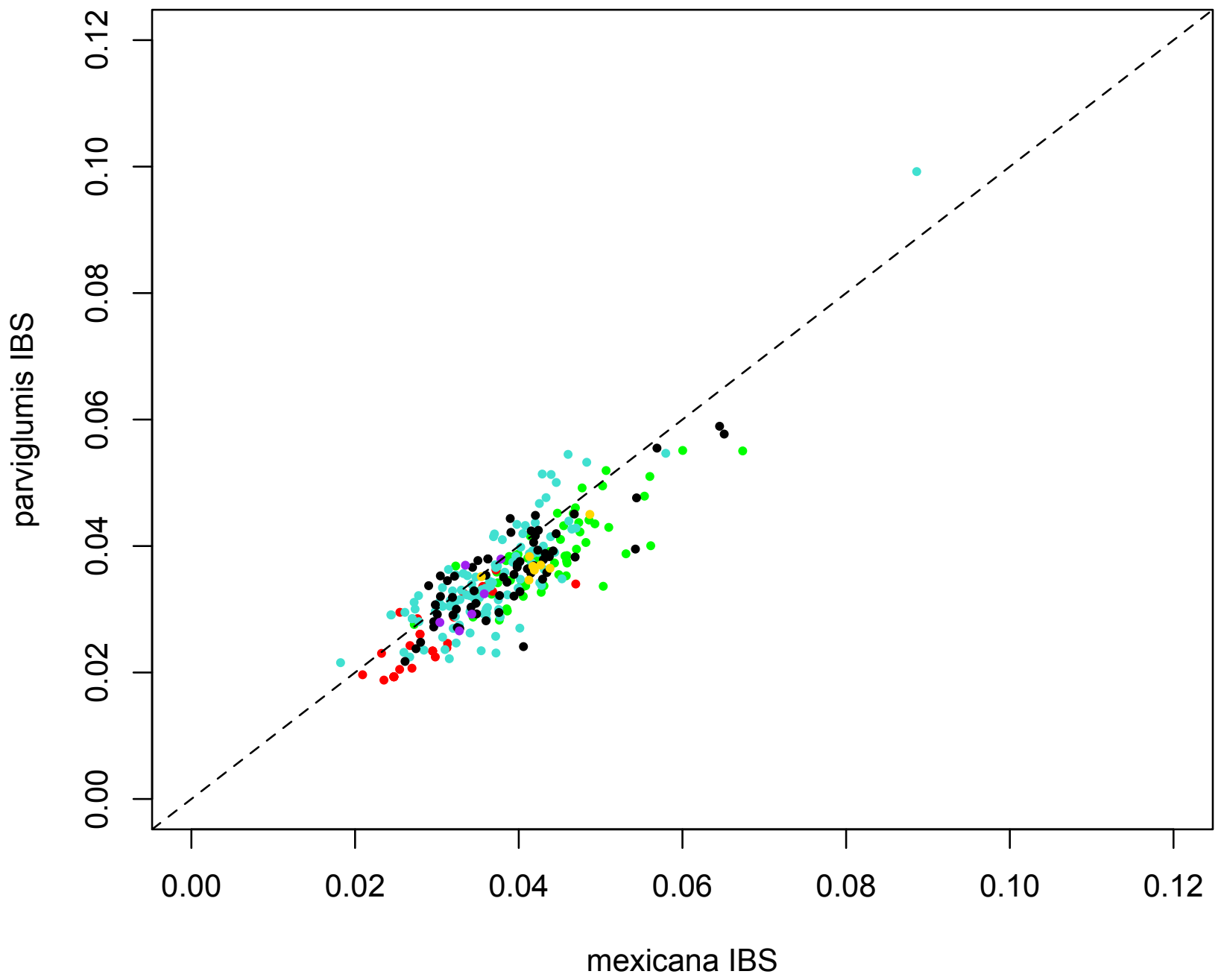

